Additional services for World Trade Review:

Email alerts: $\underline{\text { Click here }}$

Subscriptions: Click here

Commercial reprints: Click here

Terms of use : $\underline{\text { Click here }}$

\title{
Driftin' too far from shore - Why the test for compliance with the TBT Agreement developed by the WTO Appellate Body is wrong, and what should the $A B$ have done instead
}

\author{
PETROS C. MAVROIDIS
}

World Trade Review / Volume 12 / Issue 03 / July 2013, pp 509 - 531

DOI: 10.1017/S1474745613000013, Published online: 18 February 2013

Link to this article: http://journals.cambridge.org/abstract_S1474745613000013

How to cite this article:

PETROS C. MAVROIDIS (2013). Driftin' too far from shore - Why the test for compliance with the TBT Agreement developed by the WTO Appellate Body is wrong, and what should the AB have done instead. World Trade Review, 12, pp 509-531 doi:10.1017/S1474745613000013

Request Permissions : $\underline{\text { Click here }}$ 


\title{
Driftin' too far from shore - why the test for compliance with the TBT Agreement developed by the WTO Appellate Body is wrong, and what should the AB have done instead
}

\author{
PETROS C. MAVROIDIS* \\ EUI, Florence
}

\begin{abstract}
Following years of silence, the WTO Appellate Body $(\mathrm{AB})$ issued almost simultaneously three reports dealing with issues coming under the aegis of the WTO Agreement on Technical Barriers to Trade (TBT). The three Panel reports were hard to reconcile, and this feature in and of itself made the task of the $A B$ quite onerous. Some progress has been made and some clarifications have been introduced, but overall the $\mathrm{AB}$ has yet to come to grips with a coherent approach regarding the understanding of the TBT Agreement. The main argument in this paper is that the $\mathrm{AB}$, in designing its test for consistency with the TBT Agreement, did not do any different than it would have done had no TBT Agreement existed. It is, nevertheless, response to the question 'what has the TBT added to the pre-existing legislative arsenal' that should point to the elements that must be included in developing a test of consistency against which disputes coming under the aegis of the TBT Agreement should be discussed. The suggested approach consists of a two-tier test whereby Panels would first inquire into the innate characteristics of a measure coming under the aegis of the TBT Agreement, before asking the question whether it has also been applied in non-discriminatory manner.
\end{abstract}

\section{Tempest (of disputes)}

The TBT Agreement remained largely un-interpreted until the last two years. For reasons having to do with the original attitude of Panels, ${ }^{1}$ and for other reasons as

\footnotetext{
* Email: petros.mavroidis@UNINE.CH

I am highly indebted to Aaron Cosbey, Fernando Gonzalez-Rojas, Bernard M. Hoekman, Rob Howse, Jorge Huerta-Goldman, Phil Levy, Juan-Alberto Marchetti, Niall Meagher, Erik Wijkstrom, Bob Wolfe, and Alan Yanovich who participated in conferences where I presented the ideas reflected in this paper, and to Jeff Dunoff, Luca Rubini, Kamal Saggi, Joel Trachtman, Alan O. Sykes, and two anonymous referees for very helpful, critical remarks on previous drafts.

1 European Communities - Measures Affecting Asbestos and Asbestos-Containing Products, WT/DS 135 [EC-Asbestos] exemplifies the original attitude of Panels to review claims by the complainant under
} 
well, ${ }^{2}$ only one genuine TBT case had been adjudicated before 2011: EC-Sardines. ${ }^{3}$ This case dealt with some of the key provisions of the TBT Agreement, while leaving some important questions (such as the understanding of the necessity and the non-discrimination disciplines in the TBT Agreement) totally un-interpreted; as a result, it could hardly be described as authority, that is, the leading case for developing the test of consistency with the TBT Agreement.

In 2011, three cases were adjudicated almost simultaneously at the Panel-level: US-Clove Cigarettes, ${ }^{4}$ US-Tuna II (Mexico), ${ }^{5}$ and US-COOL. ${ }^{6}$ Their scope was more comprehensive than that of EC-Sardines, and WTO adjudicating bodies had to deal with almost all key provisions appearing in the TBT Agreement. ${ }^{7}$ The three Panel reports adopted irreconcilable approaches with regard to the interpretation of key terms such as 'like products' ${ }^{8}$ as a result, the task of the Appellate Body (AB) was to either pick one of the interpretations advanced (and discard the others) or advance its own interpretation that should apply from now on across TBT disputes. At the same time however, this was a good opportunity to establish a coherent test for consistency with the TBT Agreement. Alas, it failed to do so, as we detail in what follows.

A WTO Member must, when enacting a measure coming under the purview of the TBT Agreement, ensure that it is necessary to achieve the envisaged objective, that it is applied in non-discriminatory manner, and that it is, in principle, based on an international standard, assuming a relevant international standard exists. Three classes of measures come under the purview of the TBT Agreement: technical regulations, standards, and conformity assessment procedures. A technical regulation is defined in the Annex to the TBT Agreement as follows:

Document which lays down product characteristics or their related processes and production methods, including the applicable administrative provisions, with which compliance is mandatory. It may also include or deal exclusively with terminology, symbols, packaging, marking or labeling requirements as they apply to a product, process or production method.

the GATT first, and avoid reviewing their consistency with the TBT in the name of judicial economy, when both GATT and TBT were applicable.

2 The term 'dispute' here refers to disputes raised under the DSU (Dispute Settlement Understanding), that is, formal disputes adjudicated by Panels and eventually the AB. Horn et al. (2012) report that dozens of disagreements between trading partners are resolved under the aegis of the TBT Committee where they are submitted as 'specific trade concerns'. The TBT Committee acts, thus, as a filter that allows few disagreements to become formal disputes.

3 European Communities - Trade Description of Sardines, DS231 [EC-Sardines].

4 United States-Measures Affecting the Production and Sale of Clove Cigarettes, DS406 [US-Clove Cigarettes].

5 US-Final Anti-dumping Measures on Stainless Steel from Mexico, DS344 [US-Stainless Steel (Mexico)].

6 United States - Certain Country of Origin Labelling (COOL) Requirements, DS384 [US-COOL].

7 The only area now that case law has not dealt with is conformity assessment.

8 Howse and Levy (2012) offer a masterful critical discussion of the three Panel reports. 
The same Annex contains a definition of the term 'standard':

Document approved by a recognized body, that provides, for common and repeated use, rules, guidelines or characteristics for products or related processes and production methods, with which compliance is not mandatory. It may also include or deal exclusively with terminology, symbols, packaging, marking or labeling requirements as they apply to a product, process or production method. ${ }^{9}$

The three disputes concerned regulatory interventions by the US in three distinct areas that were challenged by different plaintiffs: The US had regulated market access for cigarettes, tuna, and meat products in three separate acts, the consistency of which with the obligations of the US under the TBT was contested. In US-Clove Cigarettes, the US government aimed to ban cigarettes to which juveniles were particularly addicted: it banned sales of 'clove' cigarettes without, however, taking similar measures vis-à-vis 'menthol' cigarettes (conferring, thus, an advantage to the latter). The fact that most of the domestic industry produced 'menthol' cigarettes, whereas many of the imported goods were 'clove' cigarettes prompted a challenge before the WTO that was successful. In US-Tuna II (Mexico), the US aimed at protecting the life of dolphins, and imposed certain conditions for those wishing to label their tuna products as 'dolphin-safe', while allowing other tuna products which did not meet the statutory requirements to be marketed as well without the 'dolphin-safe' label. Mexico successfully challenged the measure arguing that it was in violation of various provisions of the TBT Agreement. In US-COOL, the US adopted legislation aiming to inform consumers about the origin of goods, and to this effect imposed labelling requirements: it distinguished four categories of meat products, two of which referred to meat products wholly obtained either in the US (category A) or abroad (category D), and two others which covered meat products originating in more than one country (categories $\mathrm{B}$ and $\mathrm{C}$, which cover say meat obtained from a cow say raised in Mexico, and slaughtered in the US). Mexico and Canada successfully challenged the measure.

The US lost its argument in all three cases (both at the Panel as well as at the AB level), but the final outcome in the three disputes is immaterial for the purposes of this paper; it is the findings regarding the understanding of the following key terms appearing in the TBT Agreement that matter: 'technical regulation', 'like product', 'less favourable treatment', 'necessity', and 'legitimate objective'. These terms were decided as follows by the Panels and the AB:

Technical Regulation: in US-Tuna II (Mexico), the Panel held that a US legislation, which did not condition imports of tuna upon meeting the statutory conditions for

9 In other words, the definitions of the two instruments are similar except that compliance is necessary only with technical regulations for market access to be guaranteed. The obligations regarding conformity assessment were not an issue in the three disputes. An analysis of the legal obligation associated with conformity assessment escapes, thus, the purposes of this paper. 
the label 'dolphin-safe', but which conditioned its lawful use upon meeting certain criteria (while allowing other tuna and tuna products, which fell short of the statutory requirements for acquiring the 'dolphin-safe' label, to be marketed simply as tuna), was a technical regulation and not a standard (paras. 7.100ff., and especially paras. 7.120 and 7.131). A separate opinion issued by one member of the Panel stressed that the measure would be a 'technical regulation' only if all imported tuna had to carry the label 'dolphin-safe' in order to be marketed into the US market; this was evidently not the case here and, consequently, the challenged measure was in the eyes of this Panelist a standard and not a technical regulation (paras. 7.146ff.). The AB in paragraphs 172-199 endorsed the majority view, and held that the US measure was indeed a technical regulation; in the AB's view, what mattered was that goods had to observe the statutory requirements (and had no discretion at all to this effect), otherwise they could not legitimately be considered 'dolphin-safe'.

Like Products: in US-Clove Cigarettes, the AB held that likeness is function of the competitive relationship between two products in the market which could be informed by regulatory concerns, for example health risks. It is, thus, consumers that will decide whether two goods are like in the TBT sense of the term (paras. 110-120). In paragraphs 142-143, it underscored that likeness and DCS relationship must exist at least in some part of the market and not necessarily throughout the market. ${ }^{10}$

Less Favourable Treatment (LFT): in US-Clove Cigarettes, the Panel made it clear that, in order to show whether LFT had been afforded to imported goods, it was (para. 7.269):

required to consider whether the detrimental effect(s) can be explained by factors or circumstances unrelated to the foreign origin of the product... (emphasis in the original) ${ }^{11}$

The $\mathrm{AB}$ upheld this view in paragraphs $175 \mathrm{ff}$. of its report, adding that LFT does not exist if the detrimental impact is the outcome of pursuing legitimate objectives.

In US-COOL, the Panel found in paragraphs 7.349-7.350 that:

Turning to the scenarios involving either exclusively domestic or exclusively imported livestock, it seems logical that the scenario of processing exclusively

10 According to constant case law, two products are DCS (directly competitive or substitutable) if they are in competitive relationship to each other. It is thus consumers that will define if two goods are in similar relationship. Two goods are like if they are in intense competitive relationship (according to the most recent case law, see the $\mathrm{AB}$ report on Philippines-Distilled Spirits).

11 The same attitude is evidenced in the Panel report on US-Tuna II (Mexico) at paragraph 7.375, as well as in US-COOL paragraph 7.313: the last report went so far as to explicitly state that Article III.4 GATT was legal context for the interpretation of the LFT requirement under the TBT Agreement, paragraphs $7.234 \mathrm{ff}$. 
domestic livestock and meat is in general less costly and more viable than processing exclusively imported livestock. Livestock imports have been and remain small compared to overall US livestock production and demand, and US livestock demand cannot be fulfilled with exclusively foreign livestock. And even if it could be, in light of the evidence before us, it appears that this scenario would in all likelihood involve more than one foreign origin, and thus in general more segregation and higher compliance costs than processing exclusively domestic livestock, which by definition has one single origin. Also, in general, US livestock is often geographically closer to most if not all US domestic markets, so processing exclusively imported livestock and meat remains a relatively less competitive option.

As a result, overall, the least costly way of complying with the COOL measure is to rely on exclusively domestic livestock. Thus, in general, business scenarios involving imported livestock, including the scenario involving exclusively imported products, are overall more costly than the exclusively Label A approach.

On appeal, the $\mathrm{AB}$ first noted:

In assessing even-handedness, a panel must 'carefully scrutinize the particular circumstances of the case, that is, the design, architecture, revealing structure, operation, and application of the technical regulation at issue' (para. 271).

Following a long discussion (paras. 287ff.), the AB applied this test to the specifics of the case underscoring that detrimental impact on imported goods does not ipso facto amount to LFT; it does only if it cannot be justified as the outcome of pursuing a legitimate objective:

In sum, our examination of the COOL measure under Article 2.1 reveals that its recordkeeping and verification requirements impose a disproportionate burden on upstream producers and processors, because the level of information conveyed to consumers through the mandatory labelling requirements is far less detailed and accurate than the information required to be tracked and transmitted by these producers and processors. It is these same recordkeeping and verification requirements that 'necessitate' segregation, meaning that their associated compliance costs are higher for entities that process livestock of different origins. Given that the least costly way of complying with these requirements is to rely exclusively on domestic livestock, the COOL measure creates an incentive for US producers to use exclusively domestic livestock and thus has a detrimental impact on the competitive opportunities of imported livestock. Furthermore, the recordkeeping and verification requirements imposed on upstream producers and processors cannot be explained by the need to convey to consumers information regarding the countries where livestock were born, raised, and slaughtered, because the detailed information required to be tracked and transmitted by those producers is not necessarily conveyed to consumers through the labels prescribed under the COOL measure. This is either because the prescribed labels do not expressly identify specific production steps and, in particular for Labels B and C, contain confusing or inaccurate origin information, or because the meat or meat products are exempt from the labelling requirements 
altogether. Therefore, the detrimental impact caused by the same recordkeeping and verification requirements under the COOL measure can also not be explained by the need to provide origin information to consumers. Based on these findings, we consider that the regulatory distinctions imposed by the COOL measure amount to arbitrary and unjustifiable discrimination against imported livestock, such that they cannot be said to be applied in an even-handed manner. Accordingly, we find that the detrimental impact on imported livestock does not stem exclusively from a legitimate regulatory distinction but, instead, reflects discrimination in violation of Article 2.1 of the TBT Agreement. (para. 349, italics in the original)

In similar vein, the AB held in US-Tuna II (Mexico) (para. 297):

we conclude that the United States has not demonstrated that the difference in labelling conditions for tuna products containing tuna caught by setting on dolphins in the ETP, on the one hand, and for tuna products containing tuna caught by other fishing methods outside the ETP, on the other hand, is 'calibrated' to the risks to dolphins arising from different fishing methods in different areas of the ocean. It follows from this that the United States has not demonstrated that the detrimental impact of the US measure on Mexican tuna products stems exclusively from a legitimate regulatory distinction. We note, in particular, that the US measure fully addresses the adverse effects on dolphins resulting from setting on dolphins in the ETP, whereas it does not address mortality (observed or unobserved) arising from fishing methods other than setting on dolphins outside the ETP. ${ }^{12}$

Legitimate Objective: In US-Clove Cigarettes, the objective pursued by the US was the protection of public health; it is in the name of this objective that the US treated clove cigarettes differently from menthol cigarettes, without however providing for justification in support of the differential treatment afforded. In US-Tuna II (Mexico), the US pursued two objectives: inform consumers about the manner in which tuna had been caught; and also contribute to the protection of dolphins. Finally, in US-COOL, the US measure purported to provide consumers with information regarding the origin of the goods purchased. ${ }^{13}$

Panels have adopted a deferential (towards the regulating WTO Member) attitude when it comes to reviewing the legitimacy of an objective pursued. In US-COOL, the Panel specified that the regulating state must define its objectives and pursue them in coherent (e.g., not self-contradictory) manner, while underscoring that WTO Members remain exclusively responsible for defining the

12 The reader might be struck by the allocation of burden of (production of) proof in this paragraph: why should the US (defendant) be requested to carry the burden here and not Mexico (plaintiff)? We will revert to this discussion infra.

13 In an Appendix to the paper, we provide the relevant passages including the regulatory objectives pursued by the US as reflected in the three Panel reports. 
objectives pursued (paras. 7.611ff.). On appeal, in paragraph 372 the $A B$ confirmed this approach and added:

With respect to the determination of the 'legitimacy' of the objective, we note first that a panel's finding that the objective is among those listed in Article 2.2 will end the inquiry into its legitimacy. If, however, the objective does not fall among those specifically listed, a panel must make a determination of legitimacy. It may be guided by considerations that we have set out above, including whether the identified objective is reflected in other provisions of the covered agreements.

Necessary: In paragraph 322 of its report on US-Tuna II (Mexico), the AB explained its understanding of the necessity requirement, echoing its standard approach on this score as evidenced in its case law under Article XX GATT:

[A]n assessment of whether a technical regulation is 'more trade-restrictive than necessary' within the meaning of Article 2.2 of the TBT Agreement involves an evaluation of a number of factors. A panel should begin by considering factors that include: (i) the degree of contribution made by the measure to the legitimate objective at issue; (ii) the trade-restrictiveness of the measure; and (iii) the nature of the risks at issue and the gravity of consequences that would arise from nonfulfilment of the objective(s) pursued by the Member through the measure. In most cases, a comparison of the challenged measure and possible alternative measures should be undertaken. In particular, it may be relevant for the purpose of this comparison to consider whether the proposed alternative is less trade restrictive, whether it would make an equivalent contribution to the relevant legitimate objective, taking account of the risks non-fulfilment would create, and whether it is reasonably available. (footnote omitted)

In Section 2, we provide a critical discussion of these AB findings. Section 3 includes our suggested approach for a test of consistency with the TBT Agreement, and its application to the three disputes; Section 4 briefly recaps the main conclusions.

\section{When something is not right, it's wrong}

The AB, it is submitted, committed two errors in its treatment of the three disputes: the cardinal error is that it did not ask itself how should one understand the key terms featured in the TBT Agreement in light of the overall object and the purpose of the Agreement? Instead, it proceeded to respond to the questions asked borrowing 'lock, stock, and barrel' from its case law regarding the same terms under the GATT; it followed the sequence established in its case law (first have recourse to Article III, and then to Article XX GATT) and interpreted key terms such as 'like products' in exactly the same manner as it had interpreted them in the GATT context. As we will show infra nonetheless, by doing so it got the sequence wrong: it should have first asked whether the challenged measure were necessary and then ask the question whether they had also been applied in nondiscriminatory manner. Had it done so, it would have understood the term 
'like products' for example, as denoting policy-likeness and not market-likeness as it eventually did. The two concepts are, of course, by definition antithetical: as we will show in more detail infra, governments will intervene and 'correct' a market outcome that they do not find satisfactory.

Second, (some of) its GATT case law is far from perfect and exporting it to the TBT Agreement adds to the concerns that many have raised in the past: the boat is driftin' far from shore with the wrong load on it.

\subsection{Exporting the GATT approach into TBT: don't think twice it's alright(?)}

The AB approach across the three reports could be schematically described as follows:

(a) The AB will first ask how consumers define like products.

(b) If the response to the first question is that we are in presence of like products, it will then ask whether less favourable treatment has been afforded to imported goods as a result of the enactment of the technical regulation or standard. In this context, it will condemn measures only if they have adverse trade impact on imported goods and there is no legitimate policy rationale to justify the observed impact.

(c) It will also (assuming a claim to this effect has been raised) review the necessity of the challenged measure asking the question whether the technical regulation or standard constitutes the least restrictive option reasonably available to the regulating state.

Treating the obligations reflected in Articles 2.1 and 2.2 TBT as two distinct obligations cannot be right. Take the US-Tuna II (Mexico) as illustration. The AB will ask consumers if dolphin-safe-tuna and other tuna are like goods.

(a) If the response is no, then the US prevails, although the question will remain why would the US have to regulate if consumers behave in accordance with government preferences anyway?

(b) If the response is yes, then the $\mathrm{AB}$ will ask whether the reason for differential treatment is the origin of goods or not.

- If yes, it will find against the regulating state;

- if not, it will exonerate the regulating state from responsibility.

The AB though will never ask the question whether the US applies its measure (technical regulation or standard) in non-discriminatory manner across products of WTO origin that meet the specified regulatory requirements. The AB will respond to the question that asks whether two market-like goods (e.g., like in the eyes of consumers), one imported and one domestic, have been treated in nondiscriminatory manner; the $\mathrm{AB}$ will never ask the question whether two policy-like goods (e.g., like in the eyes of the regulator), one imported and one domestic, have been treated in non-discriminatory manner. Responding yes to the first question does not ipso facto amount to an affirmative response to the second question as well: the US could for example, deny non-discriminatory application of its 
measures to Indonesian cigarettes, Mexican tuna, and Canadian beef that meet the regulatory requirements of the challenged measures. The domain of the TBT Agreement is policy- and not market-likeness. In US-Tuna II (Mexico), for example, the question should be: Has the US applied the dolphin-safe label in nondiscriminatory manner across goods of different origin that meet the necessary regulatory requirements to have access to the label? It should not be: Are tuna and dolphin-safe tuna like products?

The $\mathrm{AB}$, thus, provided a response to the wrong question through its reports in the three cases. Accidentally, one might end up with the correct outcome. The problem, however, is that unless we get the methodology right, there is no way we can predict with reasonable certainty outcomes in future disputes. The role of the judge is to provide the methodology, the legal standard by which future disputes as well will be evaluated and not to flip a coin.

The heart of the problem, it seems, is the 'lock, stock, and barrel' export of GATT solutions (inspired by case law under Article III) to the TBT Agreement; indeed, the $\mathrm{AB}$ did nothing other than apply its test of consistency with Article III.4 GATT (as developed in Dominican Republic-Import and Sale of Cigarettes ${ }^{14}$ ) into the realm of the TBT. The GATT however, was drafted without thinking too much about disciplining regulatory barriers. ${ }^{15}$ In Baldwin's (1970) classic account, this was the right thing to do since trade barriers (e.g., high tariffs, quotas) obscured the 'bite' of regulatory barriers (e.g., domestic instruments). Under the circumstances, it was only sensible for the framers to focus on disciplining trade rather than domestic instruments. Following the Kennedy round, every round (including the on-going Doha round) has mainly focused on disciplining regulatory barriers: once again, this is only sensible since import and export quotas are illegal, and tariffs have been gradually reduced to an all-time low. The TBT is integral part of this discussion and focuses on disciplining some regulatory barriers.

Regulation at the national level is not always immune to political economy-type of considerations and, as a result, there is no guarantee that the end product will be a first best regulatory response to a market distortion. ${ }^{16}$ Linking regulation to standards such as 'scientific validity' prima facie immunizes (to a considerable extent) the regulatory process against capture. And, yet, even in this constellation there are issues to discuss: Why be more demanding (in terms of requesting scientific expertise) in one and not in another area? Or: Is it really necessary to be very risk averse when regulating a particular transaction?

14 Dominican Republic-Measures Affecting Importation and Internal Sale of Cigarettes, DS 302 [Dominican Republic-Import and Sale of Cigarettes].

15 Irwin et al. (2008) reach this conclusion after examining a very substantial percentage of the negotiating record.

16 Sykes' (1995) study remains one of the very few comprehensive studies discussing regulatory barriers against the background of world trade law. 
Moreover, regulatory capture does happen. Büthe and Mattli (2011: 135) offer the following example of regulatory capture by domestic lobbies:

A Japanese product standard ... adopted in 1986 by the Consumer Product

Safety Association (CPSA) at the request of the nascent Japanese ski manufacturing industry, required that skis sold in Japan would have to comply with particular product design specifications in order to get a consumer safety seal. None of the major foreign manufacturers met the standard. The CPSA sought to justify the introduction of the ski standard by arguing that Japanese snow is 'different' from snow in other (ski-exporting) countries.

What snow did for Japan, toys and personal computers did for others. The TBT comes into place to address this type of issue, that is, impediments to trade resulting from different regulations of similar issues. This is not necessarily the case of the GATT. In Japan-Alcoholic Beverages I and II, ${ }^{17}$ in Korea-Alcoholic Beverages, ${ }^{18}$ and in Chile-Alcoholic Beverages, ${ }^{19}$ where understanding of the term 'like products' was developed, there was no regulatory defence offered as justification for differential taxation of alcoholic drinks. Should the AB draw its inspirations from this case law when interpreting the TBT? One does not need to be a student of Wittgenstein to understand that terms are highly contextual, and not invariant. Indeed, it is the same $\mathrm{AB}$ that underscored this point when understanding the term 'like products' differently in Article III.4 GATT (dealing with non-fiscal regulatory measures) than it had done in its case law under Article III.2 GATT (dealing with fiscal regulatory measures). If the same term can have different meaning within the same provision of an agreement, should not the $\mathrm{AB}$ at least have asked whether it should have the same meaning across agreements? We discuss the term 'like products', along with the other key terms appearing in the TBT Agreement, as applied in specific cases in what follows.

\subsection{Specific issues (everything is broken)}

\subsubsection{Like products: Billy 1, Billy 4, and Billy 7 ?}

The $\mathrm{AB}$ held that two goods are like if they are in competitive relationship with each other. It is unambiguous, in the eyes of the $\mathrm{AB}$, that consumers will decide on likeness: consumers will, as the $\mathrm{AB}$ stated in a passage reminiscent of its report on EC-Asbestos, ${ }^{20}$ take into account health risks etc., but it is consumers that decide on likeness and no one else. It further stated that it suffices that two goods are like in a segment of the market, and not in the whole market. Is this the correct approach?

17 Japan-Taxes on Alcoholic Beverages I and II, DS8 [Japan-Alcoholic Beverages I and II].

18 Korea-Taxes on Alcoholic Beverages, DS75 [Korea-Alcoholic Beverages].

19 Chile-Taxes on Alcoholic Beverages, DS87[Chile-Alcoholic Beverages].

20 European Communities - EC-Measures Affecting Asbestos and Products Containing Asbestos, DS145 [EC-Asbestos]. 
In US-Tuna II (Mexico), for example, had the US not intervened and regulated the tuna market by distinguishing between tuna and 'dolphin-safe' tuna, three scenarios could in principle emerge:

(a) Consumers would treat tuna and dolphin-safe as substitutes.

(b) Consumers would never purchase tuna that is not dolphin-safe.

(c) Some consumers would treat the two products as substitutes and some would not.

In scenario (b), there would be no reason for the US government to intervene: in this case consumers as well would possess the information the government had at its disposal, and would further agree with the government's objective function in this respect (to distinguish between the two goods). Most likely then, we were in either scenario (a) or (c).

In (a), consumers would not decide what tuna to buy using the elements the government took into account when deciding on the 'dolphin-safe' label. ${ }^{21}$ The government is obviously unhappy with their behaviour and intervenes to correct the distortion; this it can do as long as a legitimate objective is being pursued, the measure is necessary to achieve the stated objective, and it is applied in nondiscriminatory manner. The likeness issue, hence, should concern the treatment of two products that pursue the same objective: likeness in the TBT-context should be understood as policy-likeness, and not as market-likeness; it should not be comparing imported tuna to domestic 'dolphin-safe' tuna, but imported to domestic 'dolphin-safe' tuna.

The fact that the TBT refers to the term 'like products' (Article 2.1 TBT) under the heading 'Preparation, Adoption and Application of Technical Regulations by Central Government Bodies' provides additional support for this point: a technical regulation is a document laying down product characteristics. ${ }^{22}$ The starting point of the analysis then must be the consistency of the technical regulation, that is the expression of the government preference, with the TBT Agreement; recall that it is product characteristics, e.g., only a sub-set of a wider product category, that are reflected in this document. Conformity with non-discrimination should, hence, be a question of conformity with the product characteristics embedded in the technical regulation. It is recourse to the necessity principle to which we will turn infra that will take care of queries regarding the well-founding of the intervention in the first place.

21 This could be the outcome for various reasons: for purely economic motives (the dolphin-safe tuna might be more expensive since the US measure adds to the fixed cost of production by imposing a particular fishing technology); or because consumers have no idea what the risks are when the number of dolphins is being reduced; or even though they know what the risks are in case the population of dolphins is gradually reduced, they do not think the life of dolphins is worth protecting or worth protecting at the cost that the more expensive tuna represents; or for other reasons (e.g., why protect dolphin and not other species and where should we draw the line etc.).

22 A similar obligation exists with respect to standards. 
The same approach should be followed in scenario (c). Recall that it is the AB that held that likeness does not have to be the case in the whole of the market; it suffices that it is the case in a segment. The $\mathrm{AB}$ did not give any numbers, but we assume it had in mind a reasonable size. This cannot be right: what if the segment of the market where tuna and 'dolphin-safe' tuna are not treated as substitutes is that encompassing the informed segment of the society, say Manhattan in New York, and the segment where they are treated as substitutes is the segment including only un-informed consumers, say Palookaville, USA? In this case, we might simply be looking at the wrong sample when following the $\mathrm{AB}$ recipe to establish likeness.

\subsubsection{Less Favourable Treatment (LFT): tangled up in blue}

Recall that in paragraph 349 of the report on US-COOL cited above, the AB had found that the treatment afforded to imported beef was less favourable than that reserved for domestic beef. This was so because the US had requested more information from producers than it had provided to consumers; this led, in the eyes of the $\mathrm{AB}$, to segregation because of the higher costs to provide documentation on multi-origin beef, than it was to provide information for beef which was exclusively of US, or Mexican, or Canadian origin. Hence, concluded, the AB, traders preferred to trade US beef. Detrimental impact, however, was not in the eyes of the $\mathrm{AB}$ enough to meet the LFT test. The question that needed to be responded to was whether the detrimental impact could be justified because it was the (involuntary) consequence of the US pursuing a legitimate objective. The AB decided that this had not been the case: because more information had been requested than disclosed (ultimately, there would be no identification of the place where each production step had taken place); because information regarding $B$ and $C$ origin was confusing and often inaccurate; and because there were exemptions from labelling obligations ('ma and pa' stores did not have to indicate origin of beef traded).

Every sentence in paragraph 349 of the $\mathrm{AB}$ report is problematic. Let us start with the discrepancy regarding the amount of information requested and eventually disclosed: this cannot be an issue when the consistency of the US measure with the obligation to not discriminate is being discussed, since more information, on the face of it, is requested from both domestic as well as imported beef. If at all, this could be an issue when the necessity of the measure is being evaluated.

The $\mathrm{AB}$ goes on and suggests that the more onerous reporting requirements applied to $\mathrm{B}$ and $\mathrm{C}$ categories (multi-origin beef) push traders to segregation and hence favour US beef. But why is it so? First, it is only normal that in case of multiorigin goods (where all stages of production must be reflected in the label), compliance will be more costly than in case of goods wholly obtained in one country. Assuming interest to enter value chains, all three (Canada, Mexico, US) will suffer from the heavier regulatory requirements to the extent that different stages of production will take place in more than one country. It could, but does not 
have to be the case, that traders might opt for goods wholly obtained in one country; we say 'it could', because there must be a reason why different stages of production occur in different places and probably the reason is purely economic. Alas, in the absence of market evidence, we will never know.

Let us assume, nevertheless, that segregation does occur. Why is it the case that US beef will be favoured as a result, and not Mexican, or Canadian, or any beef produced in one country only? How can the AB know which beef is being favoured when it has not conducted market analysis? It seems that the $\mathrm{AB}$ came up with one theoretically probable (even plausible) but unproven scenario (segregation will push traders to US beef) and then built its finding on this score around it. There are other (equally or even more) plausible scenarios though:

(a) Would, for example, traders still prefer US beef if Mexican (or Canadian, or ...) beef was significantly cheaper?

(b) Would they still prefer US beef instead of multi-origin beef if, the regulatory requirements notwithstanding, the price of multi-origin beef was substantially lower than that of US beef?

Other than a Panel opinion that traders would prefer US beef because of the geographic proximity, we have nothing in the record that suggests that segregation will lead to preference for US beef. ${ }^{23}$ If this argument is correct though, there will of course be no trade at all in the majority of products, and/or trade will be limited to only products not locally produced. This is empirically not the case (and the new trade theory provided the theoretical explanation why trade of products in the same industry occurs). The basis for the findings seems, alas, too thin to hold the claim.

Additionally, it cannot be that segregation in and of itself amounts to violation of the TBT Agreement: this was the case in Korea-Various Measures on Beef. ${ }^{24}$ In a subsequent report however (Dominican Republic-Import and Sale of Cigarettes), the $\mathrm{AB}$ held that the adverse trade impact does not amount to less favourable treatment if it is the result of a legitimate regulatory distinction. ${ }^{25}$ In this case, the $\mathrm{AB}$ did not doubt that the objective pursued by the US was legitimate: it was consumer protection.

Finally, the allocation of the burden of proof as well is problematic. The US should not be required to prove that LFT had been afforded: this is what Mexico

23 Hence, we are not here in 'raising the rival's cost' scenario. Indeed, the AB does not believe that similar market analysis is warranted since it has always construed provisions regulating non-discrimination as protecting competitive conditions; to this effect, violations can occur (in the eyes of the $\mathrm{AB}$ ) even if no data on trade effects have been provided. For a critique of this case law, see Mavroidis (2012).

24 Korea-Measures Affecting Imports of Fresh, Chilled and Frozen Beef, DS161 [Korea-Various Measures on Beef].

$25 \mathrm{It}$ is not, thus, by accident that the $\mathrm{AB}$ cites its report on Korea-Various Measures on Beef to support its segregation argument. In Mavroidis (2012), we discussed extensively the relationship between the two reports. 
should be doing in accordance with the allocation of burden of proof that the $A B$ customarily follows. Let us hope that this is simply clumsy shorthand on behalf of the drafters of the report and nothing more.

\subsubsection{Necessity analysis: saved}

Article 2.2 TBT, especially the last part of it, lays some doubt as to whether we are within the four corners of a necessity analysis (where ends are not justiciable and only means are), or whether a full proportionality analysis is called for (a 'balancing' exercise, where the need to pursue an ends is the subject-matter of the judicial review). The latter would be at odds with the negative integration character of the TBT. ${ }^{26}$ It is thus quite welcome that the AB understood in paragraph 322 of US-Tuna II (Mexico) the language in Article 2.2 TBT as a pure necessity requirement:

the nature of the risks at issue and the gravity of consequences that would arise from non-fulfilment of the objective(s) pursued by the Member through the measure. In most cases, a comparison of the challenged measure and possible alternative measures should be undertaken.

The term 'most cases' used in this paragraph might imply that there could be other cases, exceptional cases, where something more than necessity analysis might be required. One can only hope that this scenario will not materialize: it would be quite inappropriate for WTO Panels to move beyond this analysis and indulge in a balancing exercise where they decide which values societies should promote. Similar exercises exceed the current WTO mandate, which, with the exception of the TRIPs Agreement, is built around negative integration (e.g., policies are unilaterally defined and must be applied in non-discriminatory manner vis-à-vis domestic and foreign goods/services/services suppliers).

There is one problem nevertheless, with the AB's approach: it treated the necessity obligation and the obligation to not discriminate as two distinct obligations. We will revert to this discussion in Section 3.

\subsubsection{Technical regulations and standards: man gave names to all the animals}

Recall that, in US-Tuna II (Mexico), the AB held that the US measure was indeed a technical regulation although tuna could be marketed in the US market without carrying the label 'dolphin-safe'. This cannot be right.

In the standards-context (as opposed to a context where we are in presence of a technical regulation), it is not dolphin-safe tuna (as opposed to all tuna) that is lawfully marketed; if this were the case, then in US-Tuna II (Mexico) tuna that had

26 Sykes (2003) has argued that this is indeed what happens when the AB adopts a more deferential attitude towards measures aiming to protect human health than towards other social preferences. This is a correct comment, although there is absolutely no basis anywhere in the GATT that would justify this standard of review. 
been fished in a manner that did not meet the standards' requirements should ipso facto have been denied market access. This is factually incorrect: all tuna could be lawfully marketed in the US, but only some (the tuna that met the statutory requirements) could be marketed as dolphin-safe.

Consistency with standards, on the other hand, must be safeguarded: if standards can be used by products that fall short of meeting the established statutory requirements, then they ipso facto are denied of any raison d'être. Moreover, consumers will not be protected at all since products can, for example, carry the 'dolphin-safe' label irrespective whether the tuna sold has been fished in dolphin-friendly manner or not. For all these reasons, the $\mathrm{AB}$ cannot be right on this issue.

\subsection{Skeletons in the cupboard: international standards}

Prior (to the three reports discussed here) case law regarding the interpretation of the TBT Agreement has not been exemplary. Chief among the concerns that it has raised is the allocation of the burden of proof in case of deviation from an international standard. Recall that Article 2.4 TBT reads:

Where technical regulations are required and relevant international standards exist or their completion is imminent, Members shall use them, or the relevant parts of them, as a basis for their technical regulations except when such international standards or relevant parts would be an ineffective or inappropriate means for the fulfilment of the legitimate objectives pursued, for instance because of fundamental climatic or geographical factors or fundamental technological problems.

In EC-Sardines, the AB held that the burden of proof should be allocated to the complainant even in the case where the defendant has deviated from an, in principle, relevant international standard. The obvious question is how can the complainant know the reasons why a standard is ineffective or inappropriate for use by the regulating state? This should be a classic case of private information. The $\mathrm{AB}$ though pointed to the transparency requirements established in the TBT Agreement to make the point that there should be no asymmetry of information between the regulating state and the other WTO Members. But what if these requirements had been violated, or inadequately implemented? More fundamentally, it is against the background of the transparency requirements that Article 2.4 TBT explicitly refers to deviation from international standards as an exceptional circumstance. Recall that Article 2.4 TBT in relevant part reads:

except when such international standards or relevant parts would be an ineffective or inappropriate means for the fulfilment of the legitimate objectives pursued... (emphasis added)

Surprisingly, the $\mathrm{AB}$ that refers to the Oxford Dictionary in each and every report issued so far decided to overlook the meaning and the legal consequences of the term 'except' prominently appearing in the body of this provision. And yet it is 
the case, since Roman law, that the party invoking the exception carries the associated burden of proof (quicunque exceptio invokat, ejusdem probare debet). ${ }^{27}$

\section{New morning: a suggested approach}

There is one key assumption for our suggested approach to work: Articles 2.1 and 2.2 TBT are a substitute for, and not a complement to, Articles III and XX GATT. Nothing in the TBT Agreement explicitly discusses its relationship with Article XX GATT, or the GATT in general. The preamble mentions all Article XX grounds that could be relevant to the TBT Agreement, and this feature of the Agreement should denote, if at all, that its framers had in mind a construction of the TBT Agreement where no recourse to Article XX GATT would be possible. Moreover, Article 2.2 TBT includes the necessity test which appears in some sub-paragraphs of Article XX GATT.

Earlier case law suggests that the two agreements can apply simultaneously on the same transaction: indeed in EC-Asbestos, the Panel reviewed the consistency of the challenged measure with the GATT and refrained from doing the same under the TBT only in the name of judicial economy. Subsequent case law has not explicitly departed from this construction, but did not confirm it either. In fact, there are good reasons to believe that it should. In US-Clove Cigarettes, the Panel came close to discussing this issue but at the end it did not have to since the US had invoked Article XX GATT as exception to Article III GATT only, and not as exception to the TBT (paras. 7.305ff.). Perhaps the US attitude here in and of itself is telling. In US-COOL, the Panel held that the interpretation of the 'necessity requirement' should be symmetric to the interpretation of the same term under Article XX GATT (paras. 7.667ff.). Hence, under the circumstances, it will be farfetched to construct Article XX GATT as exception to the TBT since as a matter of logic it cannot be that the same measure fails and passes the same legal test (since the necessity test appears in various paragraphs of Article XX GATT, and some TBT measures could come under the purview of Article $\mathrm{XX}(\mathrm{b})$ and/or $\mathrm{XX}(\mathrm{d})$ GATT where the necessity test is present). The point here is that the TBT should be regarded as substitute and not complement to the GATT, at least with respect to Articles III and XX. ${ }^{28}$

With this in mind, the first step should be to ask whether the measure (technical regulation or standard $)^{29}$ is necessary for pursuing a legitimate objective. Here the

27 Horn and Weiler (2007) discuss the policy implications of this ruling.

28 In US - Tuna II (Mexico), the AB held that the subject matter of Article 2.1 TBT does not overlap with that of Articles I and III.4 GATT without taking, however, a firm position on the question whether violations of TBT can be justified through recourse to Article XX GATT (para. 405).

29 Both instruments must respect the necessity requirement. Measures conditioning market access of products upon satisfaction of certain product characteristics should be considered technical regulations; measures which allow the wider class of products to be marketed while reserving say a label to a sub-part of the wider class (the sub-part that respects the product characteristics established) should be considered a 
question to ask should be whether the adopted measure is the least restrictive option to achieve a unilaterally defined objective, and not a balancing test; in the absence of clear legislative mandate (as is the case), Panels are ill-equipped to rank social preferences which should be decided at the state-level. In this endeavour, Panels can ask a variety of questions, such as whether recourse should be made to performance instead of product requirements (e.g., should the US insist that a tuna product is 'dolphin-safe' only if fished through a particular fishing net, or even if fished with another, equally effective type of net?); or whether a particular type of labelling should be privileged over another type which had been tried elsewhere with similar results etc. The key point here is that the judge should ask whether the product characteristics reflected in the challenged instrument are necessary to achieve the stated objective. ${ }^{30}$ The allocation of burden of proof here should be inspired by the $\mathrm{AB}$ report on US-Gambling: 31 the complaining party could point to a measure less restrictive than the one privileged by the regulator and then it should be up to the defendant to demonstrate why the suggested option was not reasonably available to it.

If the response to the first question (is the measure the least restrictive option?) is negative, there is no need to move to the second step. In the opposite scenario, it is the non-discriminatory application of the necessary measure with Article 2.1 TBT that must be assessed. The first leg of this step will be the likeness issue. Likeness in the suggested approach should not be a matter of consumers' preferences, it should be matter of satisfying the necessary product characteristics, e.g., the government preference which has passed the hurdle of consistency with Article 2.2 TBT. The question to ask should not be whether two goods (imported, domestic) are marketlike, but whether they are policy-like. If no, then there is no need to move to the second step. If yes, then the rest of the test is a walk in the field: if products are like, the same regulatory treatment should be afforded to them.

This approach finds support in the context of the two provisions. Article 2.5 TBT reads:

A Member preparing, adopting or applying a technical regulation which may have a significant effect on trade of other Members shall, upon the request of another Member, explain the justification for that technical regulation in terms of the provisions of paragraphs 2 to 4 .

Paragraphs 2-4 refer to the necessity obligation (Article 2.2 TBT), the obligation to rescind a measure if the circumstances giving rise to it have ceased to exist

standard. If only tuna that is dolphin-safe can be marketed in the US, then we are in presence of a technical regulation; if both tuna that is and is not considered dolphin-safe can be marketed in the US, then we are in presence of a standard.

30 This is of course a non-issue when an international standard has been followed since international standards are deemed necessary to achieve the objective sought.

31 United States - Measures Affecting the Cross-Border Supply of Gambling and Betting Services, DS285 [US-Gambling] 
(Article 2.3 TBT), and to the in principle obligation to base regulatory interventions on existing international standards (Article 2.4 TBT). This is not accidental. These three paragraphs reflect the innate characteristics of a technical regulation (and/or standard, conformity assessment): the obligation to not discriminate concerns the application of measures, is included in Article 2.1 TBT, and has been excluded from the obligation to justify embedded in Article 2.5 TBT.

The test advocated here is a total reversal of the existing test, and, yet, it does not represent something that the $\mathrm{AB}$ cannot relate to. It is reminiscent of the test that the $\mathrm{AB}$ itself has developed in its case law under Article XX GATT (US-Shrimp): it is Article 2.2 TBT that is the locus to discuss the substantive consistency of a measure with the TBT (playing the role of a sub-paragraph of Article XX GATT, say Article XX(b) GATT), whereas Article 2.1 TBT emerges as the forum to discuss the consistency in the application of the challenged measure (à la the chapeau of Article XX GATT). By changing the sequence, the AB will unavoidably focus on the quintessential question to ask in the context of a dispute coming under the aegis of the TBT Agreement (is the measure necessary?), rather than digressing into issues which led it to treat the TBT Agreement as if government regulation had not happened.

Were we to apply the suggested approach to the three disputes discussed in this paper, the following would obtain:

\begin{tabular}{lll} 
& Methodology & Outcome \\
\hline US-Clove Cigarettes & incorrect & correct \\
US-Tuna II (Mexico) & incorrect & partially correct \\
US-COOL & incorrect & incorrect \\
\hline
\end{tabular}

In US-Clove Cigarettes, the US had excluded from its market all but menthol and tobacco cigarettes because it wanted to prohibit the manufacture and sale of cigarettes with certain characterizing flavours that appeal to youth. In light of the very restrictive manner in which the regulatory objective had been formulated, it would be a quixotic test to find against the US on necessity grounds. The US measure though should fail the test of consistency with Article 2.1 TBT: there is absolutely no reason to exclude menthol cigarettes from its application, and the complaining party did an excellent job demonstrating that menthol and clove cigarettes are equally addictive because of their properties. The $\mathrm{AB}$ ended up concluding as much although it adopted a wrong likeness-test: it asked whether consumers would treat menthol and clove cigarettes as substitutes. Recall however, that this is the wrong question to ask for two reasons: first, if a difference between the two cigarettes indeed exists and we are in presence of private information (as is often the case when regulation is warranted), consumers will not be aware of it and 
their opinion on likeness will be totally un-informed; second, the 'less favourable treatment' test cannot act as saving factor in similar circumstances, Recall that even if a government intervention is judged TBT-consistent, because it has not been based on the origin of the good, in similar circumstances we would not respond to the question whether two policy-like goods have been treated in nondiscriminatory manner, we would respond to a different question, namely whether two market-like goods have been distinguished by regulation because of their origin, or not. This is not, however, the domain of the TBT which cares about treatment of policy-like goods. The two questions are not substitutes: the US could have justifiably treated two unlike products in different ways and still violate its obligations to treat two policy-like goods in non-discriminatory manner. In this case, had our suggested approach been followed, the US should have been found to have acted inconsistently with its obligations by adopting a measure that it had not applied in non-discriminatory manner across policy-like products, that is, by distinguishing between menthol and clove cigarettes although the two classes of goods are policy-like as the complainant had demonstrated before the Panel.

In US-Tuna II (Mexico), the qualification of the measure was an issue: as argued above, the US measure should have been properly understood as standard and not as technical regulation. The AB's understanding of the term 'technical regulation' here risks reducing standards to redundancy. Assuming we are dealing with a standard though, one questionable aspect of the AB's findings concerns the understanding of the term 'like products' which echoes the analysis in US-Clove Cigarettes and should be dismissed on similar grounds. The 'dolphin-safe' label should pass the necessity test since the content of labelling did nothing other than inform consumers about the dangers stemming from consumption of tuna fished in ways that lead to the accidental taking of dolphin-life and the manner in which the purchased tuna had been fished. The question before the Panel should be whether the 'dolphin-safe' label had been accessible to all tuna meeting the regulatory requirements irrespective of the manner in which it had been fished. Performance requirements (e.g., all who use a fishing method for tuna which guarantees that $x$ or less quantity of dolphins will be killed will have access to a 'dolphin-safe' label) are preferable to process requirements (only those who use a particular fishing technique will have access to the 'dolphin-safe' label) for a number of reasons ranging from reaping gains from innovation to reducing the risk for protectionism by promoting a domestic technique, and shifting adjustment costs to foreign imports. The latter point is more important in our discussion. The downside is that it will require an additional effort to perform conformity assessment the cost of which should not be under-estimated. ${ }^{32}$ The US should be found at fault because it

32 Wijkstrom (2012) explains that it is exporters who bear the cost of conformity assessment in the TBT-context. A similar situation arose in the context of the US-Shrimp dispute under the GATT. The AB did request from the US to accept imports of shrimps that had been fished using a technique that differed 
adopted a standard that, although necessary to meet the stated legitimate objectives, it was applied in discriminatory manner by treating policy-like tuna products in a different way. ${ }^{33}$

In US-COOL, the $\mathrm{AB}$ should not have found against the US on the evidence before it. The measure cannot be unnecessary simply because traders are requested to provide more information than what is actually revealed to consumers. ${ }^{34}$ Think of it this way: a regulation requires a certain carbon percentage say in cement. To this effect, all industries concerned are requested to notify the relevant institution of measurements that they periodically perform during a reference period but only the yearly average should be reflected on the label. Is similar legislation unnecessary simply because the information required from traders is quantitatively more than what is being revealed to consumers? How else could we ensure that eventual outliers (assume that a variation of $20 \%$ or more beyond the annual mean is considered an outlier) will be banned if they lie beyond the acceptable statutory level? The $\mathrm{AB}$ should have instead asked whether the requested information is relevant to achieve the statutory objective. The US measure is not discriminatory either. A heavier burden is imposed on goods originating in more than one country than it is imposed on goods originating in a single country, and the burden is the same for US and foreign beef alike coming under the two categories of beef (singleor multi-origin). The AB should have hence declared here game, set, and match for the US.

\section{A simple twist of (fate) sequence}

The approach we have advocated here requires a simple twist in the sequence of analysis whereby first the question will be asked whether the measure is necessary

from the prevailing US fishing technique to the extent that it led to comparable outcomes with respect to mortality of sea turtles. The AB, nonetheless, did not pronounce on the identity of the party that should bear the cost of certification.

33 The $\mathrm{AB}$ found that the US measure was affording less favourable treatment to imported tuna (para. 270): it allowed tuna caught with driftnets in its EEZ (exclusive economic zone) to be called 'dolphin-safe' although (footnote 580) most serious threats for dolphins occur in coastal areas, i.e., within EEZ; the US at the same time disallows the 'dolphin-safe' label for tuna caught in high seas. In light of this evidence, the US argument that the certification requirement is calibrated to the risk of dolphins being hurt did not hold. Similar arguments could lead to the conclusion that the US measure was not geared towards protection of dolphin life. There is nothing like a 'disguised restriction of trade' test in the TBT-context though, and unavoidably similar arguments will have to be entertained under the 'less favourable treatment' test, or will provide input to decide whether the formulation of the legitimate objective has been coherent (e.g., not selfcontradictory as the Panel on US-COOL has held).

34 Recall that the $\mathrm{AB}$ conducted this analysis when discussing whether less favourable treatment had been accorded to imported goods. This should not be the case since, as we argued above, if the burden has been equally placed on domestic and imported goods, there is no violation of the non-discrimination obligation. The WTO (both the GATT and the TBT) do not call for efficient legislation. The AB in fact, did not find that the US legislation was unnecessary. It reversed the Panel on this score but judged that it did not possess sufficient information that would have allowed it to complete the analysis on this score. 
(and, as the case may be, based on an international standard) before inquiring into its non-discriminatory application. The change of sequence has important repercussions since the question asked with respect to whether the obligation of non-discrimination has been adhered to is drastically different from the question that the $\mathrm{AB}$ has been asking so far: in our suggested approach, Panels and the $\mathrm{AB}$ should be asking whether two policy-like goods have been treated without regard to their origin. Contextual arguments having to do with the rationale for the TBT in the first place have been advanced in support of this approach: the TBT becomes relevant only after a government has adopted a particular measure coming under its aegis, and not before this has been the case. The $\mathrm{AB}$ has, alas, treated the cases coming under the TBT as if the latter did not exist. It is time to change direction.

\title{
References
}

Baldwin, R. E. (1970), Non-Tariff Distortions in International Trade, Washington, DC: Brookings Institution.

Büthe, T. and W. Mattli (2011), The New Global Rules, Princeton, NJ: Princeton University Press.

Horn, H., P. C. Mavroidis, and E. N. Wijkstrom (2012), 'Between Transparency and Adjudication: Environmental Measures in the WTO', TBT Committee, mimeo.

Horn, H. and J. H. H. Weiler (2007), 'EC-Trade Description of Sardines: Textualism and Its Discontent', in H. Horn, and P. C. Mavroidis (eds.), The WTO Case Law of 2001-2003: The American Law Institute Reporters' Studies, Cambridge: Cambridge University Press, pp. 551-578.

Howse, R. and P. Levy (2012) 'The TBT Panels: US-Clove Cigarettes, US-Tuna, and US-COOL, in C. P. Bown and P. C. Mavroidis (eds.), The WTO Case Law of 2011, The American Law Institute Reporters' Studies, Cambridge: Cambridge University Press.

Irwin, D. A., P. C. Mavroidis, and A. O. Sykes (2008), The Genesis of the GATT, Cambridge: Cambridge University Press.

Mavroidis, P. C. (2012), Trade in Goods, Oxford: Oxford University Press.

Sykes, A. O. (1995), Product Standards for Internationally Integrated Goods Markets, Washington, DC: Brookings Institution.

- (2003), 'The Least Restrictive Means', University of Chicago Law Review, 70: 403-416.

Wijkstrom, E. N. (2012), 'A Matter of Trust: Conformity Assessment in a More Complex'. World, ISO Focus: 8-11.

\section{Appendix: The objectives sought by the US in the three disputes}

US-Clove Cigarettes, paragraph 2.4 of the Panel report:

The measure at issue is Section 907(a)(1)(A) of the Federal Food, Drug and Cosmetic Act ('FFDCA'), which was added to the FFDCA by Section 101(b) of the Family Smoking Prevention and Tobacco Control Act ('FSPTCA'). Section 907(a) (1)(A) reads as follows:

\author{
'SEC. 907. TOBACCO PRODUCT STANDARDS. \\ (a) IN GENERAL. - \\ (1) SPECIAL RULES. - \\ (A) SPECIAL RULE FOR CIGARETTES. - Beginning 3 months after the date \\ of enactment of the Family Smoking Prevention and Tobacco Control Act,
}


a cigarette or any of its component parts (including the tobacco, filter, or paper) shall not contain, as a constituent (including a smoke constituent) or additive, an artificial or natural flavor (other than tobacco or menthol) or an herb or spice, including strawberry, grape, orange, clove, cinnamon, pineapple, vanilla, coconut, licorice, cocoa, chocolate, cherry, or coffee, that is a characterizing flavor of the tobacco product or tobacco smoke. Nothing in this subparagraph shall be construed to limit the Secretary's authority to take action under this section or other sections of this Act applicable to menthol or any artificial or natural flavor, herb, or spice not specified in this subparagraph.

The Panel notes that the objective of Section $907(\mathrm{a})(1)(\mathrm{A})$ is not set forth in the FSPTCA itself. However, both parties have referred the Panel to a report prepared by the House Energy and Commerce Committee ('House Report') after favourably reporting the legislation out of that Committee. The House Report explains the meaning of each section of the FSPTCA and articulates both the objectives of the FSPTCA overall, and of Section 907(a)(1)(A) in particular. According to the House Report:

The objectives of [the FSPTCA] are to provide the Secretary with the proper authority over tobacco products in order to protect the public health and to reduce the number of individuals under 18 years of age who use tobacco products.

The House Report explains the purpose of Section 907(a)(1) in particular:

Consistent with the overall intent of the bill to protect the public health, including by reducing the number of children and adolescents who smoke cigarettes, section $907(a)(1)$ is intended to prohibit the manufacture and sale of cigarettes with certain 'characterizing flavors' that appeal to youth.

US-Tuna II (Mexico), paragraphs $2.3 \mathrm{ff} .$, 7.401, and 7.425 of the Panel report:

The Dolphin Protection Consumer Information Act (DPCIA) is codified in Title 16, Section 1385 of the United States Code (USC). Regulations promulgated in accordance with the DPCIA are codified in Title 50, Section 216 of the Federal Regulations. The core of the US 'dolphin-safe' labelling scheme is contained in subsection 1385(d)(1)-(3) of the DPCIA. Paragraph (d) of Section 1385 of the DPCIA provisions regulates the use of the term 'dolphin-safe' when it appears on tuna products.

As described above, the United States itself initially identified two objectives of the US dolphin-safe provisions:

ensuring that consumers are not misled or deceived about whether tuna products contain tuna that was caught in a manner that adversely affects dolphins; and 
contributing to the protection of dolphins, by ensuring that the US market is not used to encourage fishing fleets to catch tuna in a manner that adversely affects dolphins.

Therefore, for the purposes of our analysis of Mexico's claims under Article 2.2 of the TBT Agreement, we accept the United States' representation of the objectives of the US dolphin-safe provisions as described in paragraph 0 above.

US-COOL, paragraph 6.113 of the Panel report:

The Panel rejects the United States' request for the following reasons. Based on the United States' arguments in the panel proceedings, the Panel decided that the objective as identified by the United States was 'to provide consumer information on origin'. The Panel was not presented with the argument from the United States that the reduction of compliance costs for market participants also formed part of the objective pursued by the United States through the COOL measure. As Mexico points out, the United States submitted that reducing compliance costs was one of the factors that it considered in implementing the COOL measure to achieve the objective of providing consumer information on origin. Reducing compliance costs therefore cannot form part of the objective itself. 